\title{
Revisão: Composição química, propriedades funcionais e aplicações tecnológicas da semente de chia (Salvia hispanica L) em alimentos
}

Review: Chemical composition, functional properties and technological applications of chia (Salvia hispanica L) seeds in foods

\section{Autores | Authors}

Michele Silveira COELHO

Universidade Federal do Rio Grande (FURG)

Escola de Química e Alimentos Laboratório de Tecnologia de Alimentos Rio Grande/RS - Brasil e-mail:michelecoelho_@hotmail.com

凶 Myriam de las Mercedes

SALAS-MELLADO

Universidade Federal do Rio Grande (FURG)

Escola de Química e Alimentos Laboratório de Tecnologia de Alimentos Av. Itália Km 8, Bairro Carreiros CEP: 96203-900 Rio Grande/RS - Brasil e-mail:mysame@yahoo.com

$\triangle$ Autor Correspondente / Corresponding Author

Recebido: Maio 05, 2014 Aprovado: Jan. 15, 2015

\section{Resumo}

A chia (Salvia hispanica L.) é uma semente antiga utilizada pelos maias e astecas como alimento para aumentar a resistência física. Essa semente é fonte natural de ácidos graxos ômega-3, fibras e proteínas, além de outros componentes nutricionais importantes, como os antioxidantes. Além disso, oferece um potencial na indústria de alimentos devido aos seus componentes funcionais, com aplicações no enriquecimento de pães, bolos e barras de cereais, produção de hidrolisados proteicos para aplicação em produtos de panificação, produção de maionese com adição de mucilagem de chia, entre outros produtos. Esta revisão tem como objetivo apresentar as possíveis aplicações em alimentos, demonstrando o quanto a chia ainda pode ser explorada nessa área.

Palavras-chave: Alimentos; Chia; Indústria; Funcional.

\section{Summary}

Chia (Salvia hispanica L.) is an ancient seed used by the Mayas and Aztecs as an endurance-boosting food. This seed is a natural source of omega-3 fatty acids, fibre and protein as well as containing other important nutritional components such as antioxidant agents. Moreover, the functional components of chia seeds offer various applications in the food industry, such as the enrichment of breads, cakes and cereal bars, production of protein hydrolysates for use in bakery products and the production of mayonnaise with the addition of chia mucilage. This review aims to present its possible applications in foods, demonstrating how much chia could further be explored in the food industry.

Key words: Food; Chia; Industry; Functional. 
Composição química, propriedades funcionais e aplicações tecnológicas da semente de chia (Salvia hispanica L) em alimentos

COELHO, M. S. e SALAS-MELLADO, M. M.

\section{Introdução}

As sementes de chia (Salvia hispanica L.) foram um importante alimento básico para mesoamericanos em tempos pré-colombianos (REYES-CAUDILLO et al., 2008), sendo consumidas principalmente pelos maias e astecas para aumentar a resistência física. No entanto, a chia também estava atrelada a rituais sagrados e servia como oferenda aos deuses dessas civilizações, o que despertou a ira de espanhóis católicos que viam a cerimônia como um ritual pagão. Com isso, seu cultivo foi extinto por séculos e só foi retomado no início da década de 90 por um grupo de pesquisadores argentinos em parceria com a Universidade do Arizona (EUA) (AYERZA e COATES, 2005). Desde então, os cientistas têm se voltado para pesquisas com o grão.

A chia é uma planta herbácea anual que pertence à família Lamiaceae. Tem sido cultivada no México há séculos e as sementes embebidas em água ou suco de frutas foram e ainda são consumidas em algumas regiões como bebida refrescante (CAHILL, 2003). Recente avaliação de suas propriedades e possíveis utilizações mostrou que esta possui um elevado valor nutricional com alto conteúdo de ácido $\alpha$-linolênico (ômega-3) e linoleico (ômega-6), antioxidantes, fibra dietética e proteína (PEIRETTI e GAI, 2009). A presença desses ácidos graxos na dieta garante uma diminuição da ocorrência de doenças cardiovasculares, visto que doenças crônicas continuam sendo a principal causa de morte e de incapacidade nos países industrializados e que também estão crescendo rapidamente nos países não industrializados (AHA, 2004). Há evidências epidemiológicas de que as dietas que promovem a saúde são ricas em fibras alimentares e ômega-3 e pobres em gordura saturada, gordura trans e colesterol (HU, 2002). Além disso, as sementes de chia são promissoras como fontes de antioxidantes, devido à presença de polifenóis (REYES-CAUDILLO et al., 2008). Há evidências de que a semente de chia pode trazer benefícios à saúde. Com o consumo de $25 \mathrm{~g}$ de semente de chia por dia durante 7 semanas há elevação dos níveis plasmáticos de ácido $\alpha$-linolênico e ácido eicosapentaenoico em mulheres pós-menopausa em $138 \%$ e 30\%, respectivamente (JIN et al., 2012). Chicco et al. (2009), investigando os benefícios da ingestão de semente de chia sobre dislipidemia e resistência à insulina induzida, pelo consumo de uma dieta rica em sacarose (62,5\%), sobre ratos durante três semanas, demonstraram que a semente de chia impediu o início da dislipidemia e resistência à insulina, e a glicemia não se alterou. Além disso, quando a semente de chia forneceu a gordura durante os últimos dois meses do período de alimentação reduziu a adiposidade visceral presente nos ratos.

Substituir ingredientes menos nutritivos por outros de maior valor nutricional, sem comprometer o sabor dos alimentos, é uma prática de relevância para se constituir uma dieta saudável. A chia é particularmente interessante dentro dessa lógica, que, além de melhorar o valor nutritivo, apresenta grande capacidade para reter água e óleo, características que fazem dela uma candidata natural como aditivo para produtos panificados e como emulsão alimentar (OLIVOS-LUGO et al., 2010). Assim, devido às suas propriedades, o enfoque desta revisão foi apresentar diversas possibilidades de utilização da chia na indústria de alimentos.

\section{A semente de chia (Salvia hispanica L.) e sua composição química}

A chia (Figura 1) é cultivada comercialmente no México, Bolívia, Argentina, Equador e Guatemala (COATES e AYERZA, 1996). Juntamente com a chia, o milho, o feijão e o amaranto foram os alimentos mais importantes de mais de 11 milhões de pessoas quando Colombo chegou à América. A chia também foi utilizada como uma oferenda aos deuses de Nahua (SAHAGUN,
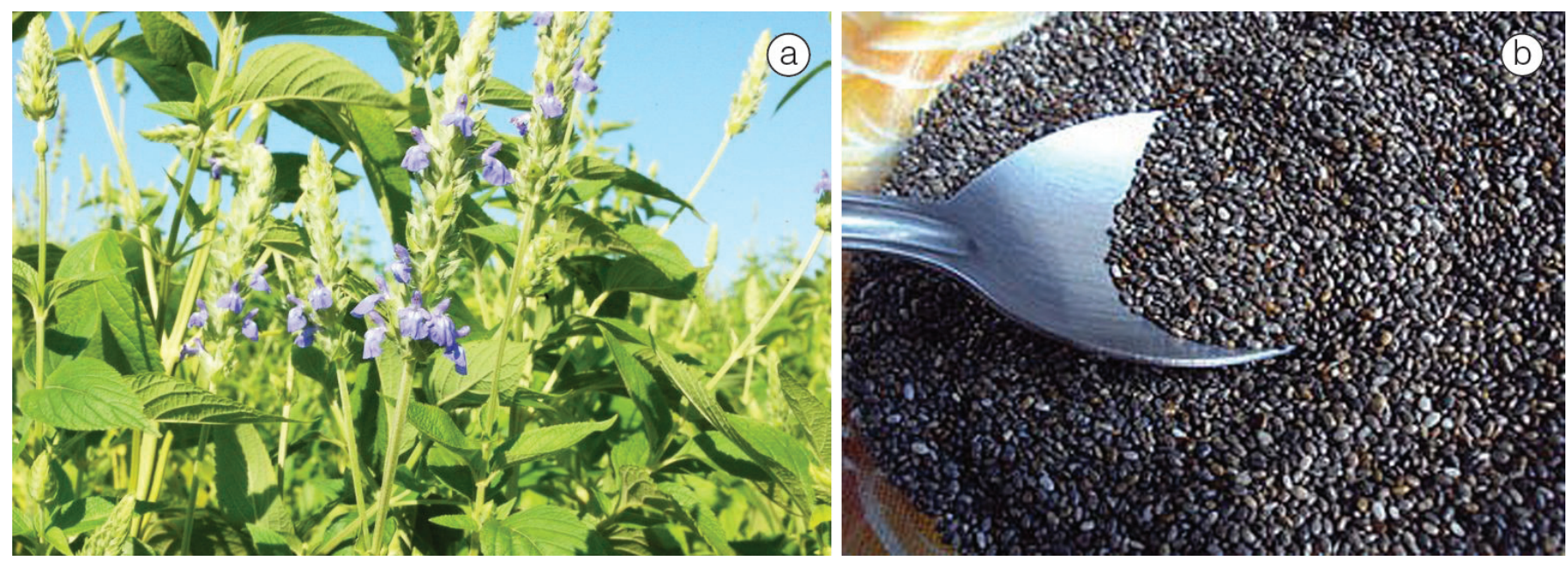

Figura 1. Plantação de chia (a) e sementes de chia (b) (TOSCO, 2004). 
COELHO, M. S. e SALAS-MELLADO, M. M.

1989) devido à perseguição religiosa, e, dado o fato de que não pôde ser cultivada na Europa, desapareceu no século XVI. A chia pode crescer até $2 \mathrm{~m}$ de altura e possui um rendimento médio de $250 \mathrm{~g}$ de sementes por pé, sendo a melhor época de produção entre outubro e novembro, onde há chuvas espaçadas e calor.

As sementes de chia são utilizadas como suplementos nutricionais, bem como na fabricação de barras, cereais matinais e biscoitos nos Estados Unidos, América Latina e Austrália (DUNN, 2010). Possuem uma quantidade significativa de lipídios (cerca de 40\% do peso total da semente, sendo quase $60 \%$ como ômega-3) e também fibra dietética (mais de $30 \%$ do peso total), ambos componentes importantes da dieta humana, e proteínas de elevado valor biológico (cerca de 19\% do peso total). Além disso, contém minerais, vitaminas e antioxidantes naturais como tocoferóis (238-427 mg. $\mathrm{kg}^{-1}$ ) e polifenóis, sendo os principais compostos fenólicos o ácido clorogênico, ácido cafeico, quercetina e kaempferol (IXTAINA et al., 2011), que protegem os consumidores contra algumas condições adversas, tais como doenças cardiovasculares e certos tipos de câncer (AYERZA e COATES, 2004; CRAIG, 2004).

A semente de chia é uma boa fonte de proteína (19-27 g.100 g ${ }^{-1}$ ) (WEBER et al., 1991). O conteúdo de proteína é mais elevado do que a de outras culturas tradicionais, tais como milho, trigo, arroz, aveia, cevada e amaranto (AYERZA e COATES, 2005). Embora a chia não seja cultivada comercialmente como uma fonte de proteína, o seu perfil de aminoácidos não tem fatores limitantes na dieta do adulto (BUSHWAY et al., 1981), mas treonina, leucina e lisina são os aminoácidos limitantes na dieta de uma criança na época pré-escolar (WEBER et al., 1991). A Tabela 1 apresenta a composição da chia segundo Puig e Haros (2011) e Bushway et al. (1981).

As sementes de chia são uma importante matériaprima para a obtenção de alimentos funcionais devido às suas características especiais, oferecendo vantagens em relação a outras fontes disponíveis (COATES e AYERZA, 1996). A chia é ideal para o enriquecimento de

Tabela 1. Composição química e teor de vitaminas de sementes de chia (Salvia hispanica L.) em base seca.

\begin{tabular}{lc}
\multicolumn{1}{c}{ Componentes } & Conteúdo \\
\hline Lipídios $\left(\mathrm{g} \cdot 100 \mathrm{~g}^{-1}\right)^{\mathrm{a}}$ & 33,9 \\
Proteínas $\left(\mathrm{g} \cdot 100 \mathrm{~g}^{-1}\right)^{\mathrm{a}}$ & 20,2 \\
Cinzas $\left(\mathrm{g} \cdot 100 \mathrm{~g}^{-1}\right)^{\mathrm{a}}$ & 2,33 \\
Fibra dietética $\left(\mathrm{g} \cdot 100 \mathrm{~g}^{-1}\right)^{\mathrm{a}}$ & 43,1 \\
Niacina $\left(\mu \mathrm{g} \cdot \mathrm{g}^{-1}\right)^{\mathrm{b}}$ & 82,50 \\
Riboflavina $\left(\mu \mathrm{g} \cdot \mathrm{g}^{-1}\right)^{\mathrm{b}}$ & 2,13 \\
Tiamina $\left(\mu \mathrm{g} \cdot \mathrm{g}^{-1}\right)^{\mathrm{b}}$ & 14,42 \\
Vitamina A $\left(\mu \mathrm{g} \cdot \mathrm{g}^{-1}\right)^{\mathrm{b}}$ & 43,0 \\
\hline
\end{tabular}

a Puig e Haros (2011); b Bushway et al. (1981). certo número de produtos como alimentos para bebês, alimentos assados, barras de cereais, iogurtes e molhos (JUSTO et al., 2007).

\section{1 Ácidos graxos essenciais}

O consumo de ácido graxo ômega-3 favorece a deformação dos eritrócitos e diminui a viscosidade do sangue, mesmo em doses baixas. Esses efeitos facilitam a microcirculação e possibilitam maior oxigenação dos tecidos (MENDONÇA, 2010). Além disso, o consumo frequente de alimentos ricos em ômega-3 reduz os níveis de colesterol e triglicerídios no sangue, e também reduz a pressão arterial, havendo associação a menores índices de doença cardiovascular. A partir da sua ingestão há a biossíntese no organismo dos ácidos graxos EPA (eicosapentaenoico, C20:5) e DHA (docosahexaenoico, C22:6), os quais, embora tenham uma estrutura semelhante, desempenham funções fisiológicas e metabólicas muito diferentes. O EPA relaciona-se principalmente com a proteção da saúde cardiovascular no adulto e o DHA é considerado fundamental para o desenvolvimento do cérebro e do sistema visual, o que a associa à saúde materno-infantil (ZAMBOM et al., 2004).

Além de seu papel nutricional na dieta, os ácidos graxos ômega-3 podem ajudar a prevenir ou tratar uma variedade de doenças, incluindo doenças do coração, câncer, artrite, depressão, mal de Alzheimer, entre outros (MORAES e COLLA, 2006).

A chia é rica em ácidos graxos poli-insaturados (PUFA), particularmente ácido $\alpha$-linolênico, o ômega-3 (COELHO e SALAS-MELLADO, 2014) (Tabela 2). A presença desses ácidos graxos na dieta de indivíduos promove uma redução na incidência de doenças cardiovasculares, em que tanto os peixes como as plantas marinhas são considerados os mais importantes mediadores dessa redução em experimentos controlados (DE LOGERIL e SALEN, 2007). Entretanto, outros autores (CUNDIFF et al., 2007) associam os benefícios do consumo de pescado não somente à sua riqueza em PUFA, mas também ao consumo de uma dieta saudável.

Como as autoridades de saúde e alimentação recomendam diminuir a ingestão de gordura saturada e aumentar a ingestão de fibras, proteínas e ácidos graxos ômega-3, seja pelos meios convencionais tais como o aumento do consumo de sementes vegetais ou produtos marinhos, ou através do desenvolvimento e consumo de alimentos enriquecidos com esses componentes, a chia é uma alternativa promissora para o aumento desses componentes na dieta, já que é rica em PUFA's, proteínas, fibras e compostos fenólicos que possuem atividade antioxidante. Coelho e Salas-Mellado (2015) adicionaram a chia em pães de farinha de trigo reduzindo o teor de gordura vegetal hidrogenada nas formulações, gerando dois novos produtos: pão adicionado de 7,8\% de farinha 
Composição química, propriedades funcionais e aplicações tecnológicas da semente de chia (Salvia hispanica L) em alimentos

COELHO, M. S. e SALAS-MELLADO, M. M.

Tabela 2. Conteúdo de lipídios e composição de ácidos graxos da semente de chia (Salvia hispanica L.)*

\begin{tabular}{|c|c|}
\hline & $\mathrm{g} .100 \mathrm{~g}^{-1}$ \\
\hline Lipídios & 34,39 \\
\hline Gorduras saturadas & 9,74 \\
\hline Ácido mirístico (C14:0) & 0,03 \\
\hline Ácido pentadecanoico (C15:0) & 0,03 \\
\hline Ácido palmítico (C16:0) & 6,69 \\
\hline Ácido margárico (C17:0) & 0,06 \\
\hline Ácido esteárico (C18:0) & 2,67 \\
\hline Ácido behênico (C22:0) & 0,09 \\
\hline Ácido tricosanoico (C23:0) & 0,03 \\
\hline Ácido lignocérico (C24:0) & 0,14 \\
\hline Gorduras monoinsaturadas & 10,76 \\
\hline Ácido pentadecenoico (C15:1) & 0,03 \\
\hline Ácido palmitoleico (C16:1) & 0,09 \\
\hline Ácido oleico (C18:1- $\omega-9)$ & 10,55 \\
\hline Ácido cis-eicosenoico (C20:1) & 0,09 \\
\hline Gorduras poli-insaturadas & 79,47 \\
\hline Ácido linoleico (C18:2- $\omega-6)$ & 17,36 \\
\hline Ácido linolênico (C18:3- $\omega-3)$ & 62,02 \\
\hline Ácido cis-eicosadienoico (C20:2) & 0,03 \\
\hline Ácido cis-eicosatrienoico (C20:3) & 0,03 \\
\hline Gordura trans & 0,03 \\
\hline Ácido elaidico (C18:1) & 0,03 \\
\hline Gorduras insaturadas & 90,26 \\
\hline
\end{tabular}

*\% do total de lipídios. Fonte: Coelho e Salas-Mellado (2014).

de chia e 0,9\% de gordura e pão adicionado de $11 \%$ de semente de chia e 1\% de gordura gerando uma redução de $27 \%$ e $24 \%$ de gordura saturada, respectivamente, em relação ao pão controle feito com farinha de trigo. Como resultados, obtiveram um aumento dos teores de gordura poli-insaturada em 195\% e 125\%, principalmente ômega-3, com aumentos de 61,7 e 40,3 vezes, além de aumentar os teores de fibras em 19 e 6,67 vezes, respectivamente, apresentando os pães características de produtos funcionais.

\subsection{Compostos fenólicos}

Embora indispensável para a vida, o oxigênio pode causar danos ao organismo, já que o metabolismo celular promove a formação de radicais livres (BARROS et al., 2008; KITZBERGER, 2005). Esses radicais oxidam vários compostos como proteínas, ácidos nucleicos, DNA e lipídios, podendo levar à formação de doenças degenerativas (PRAKASH et al., 2014). O interesse no estudo dos compostos fenólicos tem aumentado muito, devido principalmente à habilidade antioxidante dessas substâncias em sequestrar radicais livres, os quais são prejudiciais à saúde humana (DORMAN et al., 2003).

Os compostos fenólicos têm sido considerados os mais importantes, numerosos e onipresentes grupos de compostos do reino vegetal e são sintetizados durante o desenvolvimento normal da planta, bem como em resposta a diferentes situações, como estresse e radiação UV, entre outros (NACZK e SHAHIDI, 2004). Os compostos fenólicos são substâncias formadas por, no mínimo, um anel aromático, em que pelo menos um hidrogênio é substituído por um grupo hidroxila, encontrado sob a forma de ésteres ou de heterosídeos, e não na forma livre na natureza (SIMÕES et al., 2000). Estes podem ser classificados em compostos solúveis em água (ácidos fenólicos, fenilpropanoides, flavonoides e quinonas) e compostos insolúveis em água (taninos condensados, ligninas e paredes celulares ligados a ácidos hidroxicinâmicos) (RISPAIL et al., 2005). O comportamento dos compostos antioxidantes fenólicos está relacionado com a sua capacidade de quelar metais, inibir a lipoxigenase e capturar os radicais livres, como o 2,2-difenil-1-picril-hidrazila (DPPH), embora, ocasionalmente, também possa promover reações de oxidação in vitro (DECKER, 1997).

A chia tem um grande potencial dentro da indústria alimentícia, dado que a sua oxidação é mínima, comparada com outras fontes de ômega-3 como a linhaça, que apresenta uma decomposição rápida devido à ausência de antioxidantes (TOSCO, 2004). A semente de chia contém uma quantidade de compostos com potente atividade antioxidante devido a substâncias como miricetina, quercetina, kaempfenol e ácido cafeico. Esses compostos são antioxidantes primários e sinérgicos que contribuem para a sua potente atividade antioxidante. A importância destes é a atividade contra a oxidação de lipídios que afeta não só a qualidade dos alimentos como também a saúde do consumidor (CASTROMARTINEZ et al., 1986; TAGA et al., 1984).

Reyes-Caudillo et al. (2008) estudaram o perfil de compostos fenólicos de sementes de chia de duas regiões do México, sendo que o ácido clorogênico foi o predominante no extrato bruto de compostos fenólicos da chia, variando de 45,9-102 $\mu \mathrm{g} \cdot \mathrm{g}^{-1}$ chia seguida por ácido cafeico (3-6,8 $\left.\mu \mathrm{g} \cdot \mathrm{g}^{-1} \mathrm{chia}\right)$. Ainda segundo esses autores, essas diferenças podem ser explicadas pelo fato de que o conteúdo de compostos fenólicos é afetado por uma série de fatores externos, tais como condições meteorológicas e de pós-colheita. Kim et al. (2006) sugeriram a utilização de dois diferentes métodos de extração, a fim de obter maiores informações sobre a concentração de compostos fenólicos em sementes de chia. Isso porque os compostos fenólicos podem estar na forma de polímeros, ésteres e glicosídeos sendo então indicada a hidrólise enzimática para quantificar e verificar a biodisponibilidade desses compostos. Ainda não há relatos de estudos utilizando os compostos fenólicos extraídos de chia para aplicação em alimentos. 
COELHO, M. S. e SALAS-MELLADO, M. M.

\subsection{Proteínas}

O percentual de proteínas (19\%-23\%) da semente de chia, semelhante ao da lentilha (23\%), ervilha (25\%) e grão de bico (21\%) (OLIVOS-LUGO et al., 2010; IXTAINA et al., 2008), é indicativo para a sua utilização como fonte de nutrientes para animais e seres humanos, já que a semente contém todos os aminoácidos essenciais necessários para a nutrição humana (RUPFLIN, 2011). As principais proteínas de sementes de chia são proteínas de armazenamento, representando cerca de 60\%-80\% do total de proteína (SHEWRY, 2002), e sua análise é complicada pela heterogeneidade dos polipeptídeos e os diferentes comportamentos de solubilidade. As globulinas são as maiores frações na semente de chia (SANDOVALOLIVEROS e PAREDES-LÓPEZ, 2013).

O consumo de sementes de chia fornece inúmeros benefícios à saúde e as proteínas podem ser disponibilizadas como peptídeos biologicamente ativos. Os peptídeos, em geral, podem desempenhar diversas atividades, com base na sua composição e sequência de aminoácidos, tais como: imunomodulatória, antimicrobiana, antitrombótica, hipocolesterolêmica, antihipertensiva e antioxidante, e o grau de hidrólise é o principal fator que afeta a atividade biológica nos hidrolisados proteicos de chia. Segura-Campos et al. (2013) verificaram que a inclusão dos hidrolisados de chia, de 1 e $3 \mathrm{mg} \cdot \mathrm{g}^{-1}$ em pão branco e creme de cenoura, aumentou a atividade antioxidante e atividade inibitória da enzima conversora de angiotensina I, sem afetar notavelmente a qualidade do produto. Mas nenhuma atividade antimicrobiana foi observada nos hidrolisados de chia, uma vez que o elevado grau de hidrólise (16,1\% a $43,8 \%$ ) resultou em menor comprimento da cadeia de seus peptídeos constituintes, impedindo-os de desintegrar a membrana da célula microbiana.

O isolado proteico de chia apresenta valores de capacidade de retenção de água e óleo de $4,06 \mathrm{~g} \cdot \mathrm{g}^{-1} \mathrm{e}$ $4,04 \mathrm{~g} \cdot \mathrm{g}^{-1}$, respectivamente, o que sugere uma elevada proporção de resíduos hidrofóbicos. Considerando-se estas propriedades, proteínas de chia têm potencial para utilização como ingrediente funcional em muitas aplicações alimentares, tais como salsichas e emulsões alimentares (OLIVOS-LUGO et al., 2010). A fração protéica da farinha de chia pode ser explorada como um ingrediente nutricional atraente em produtos alimentícios processados, principalmente devido à tendência dos consumidores na escolha de alimentos associado à saúde e bem-estar. A proteína isolada a partir de fontes vegetais é de interesse devido a sua utilização como ingredientes com propriedades funcionais (PAREDES-LÓPEZ et al., 1985; SEGURA-NIETO et al., 1999).

\subsection{Fibra alimentar}

A alta quantidade de fibras da semente de chia $(34,6 \%)$ pode aumentar a saciedade e diminuir o consumo de energia (OLIVOS-LUGO et al., 2010; AYERZA et al., 2002). A sua ingestão também tem efeitos benéficos para a superação de fatores de risco associados ao aparecimento de várias doenças crônicas, além de muitas doenças de importância para a saúde pública como a obesidade, doenças cardiovasculares e diabetes do tipo 2 (OLIVOS-LUGO et al., 2010).

Quando mergulhadas em água, as sementes de chia exsudam um gel transparente mucilaginoso que permanece firmemente ligado à semente. No epicarpo da semente encontram-se células que produzem mucilagem quando umedecidas. Ao entrar em contato com a água, o epicarpo incha, a cutícula se rompe ao esgotar a sua elasticidade e o conteúdo das células verte como mucilagem circundando toda a superfície da semente (IXTAINA et al., 2010). Esse gel é composto essencialmente de xilose, glicose e ácido glicurônico, formando um polissacarídeo ramificado de alto peso

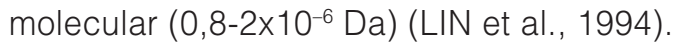

Segundo Gômes e Colín (2008), a mucilagem de chia é um polissacarídeo útil como fibra solúvel e dietética. Além disso, Capitani et al. (2012) afirmaram que as frações fibrosas de chia evidenciam uma grande capacidade de reter e absorver água, podendo ser utilizada como um agente emulsionante e estabilizante de emulsões. O consumo dessa fibra dietética pode ser uma importante alternativa para melhorar a saúde humana. Em 1996, a semente de chia foi descrita pela FAO como uma fonte potencial de goma polissacarídica devido às suas excepcionais propriedades mucilaginosas em solução aquosa e baixa concentração (MUÑOZ et al., 2012a). O gel formado, quando ingerido, produz uma barreira física que separa as enzimas digestivas dos carboidratos, promovendo uma lenta conversão de carboidratos em açúcar, consequentemente uma digestão lenta. Além disso, mantém os níveis de açúcares no sangue sendo útil na prevenção e controle da diabetes.

As sementes de chia contêm 5\%-6\% de mucilagem, que pode ser utilizada como fibra dietética (AYERZA e COATES, 2001; REYES-CAUDILLO et al., 2008). Muñoz et al. (2012a) estudaram a capacidade de hidratação da mucilagem de chia, sendo que uma amostra de $100 \mathrm{mg}$ de mucilagem foi capaz de absorver 2,7 g de água, 27 vezes o seu próprio peso. Adams et al. (1986) e Grigelmo-Miguel e Martín-Belloso (1998) concluíram em seus estudos que quanto maior o teor de fibra dietética solúvel maior a capacidade de retenção de água. Uma patente refere-se a sua extração através de ultrassons e de alta pressão de filtração (MARIN et al., 2008), mas outras informações são necessárias sobre as condições de extração, os 
COELHO, M. S. e SALAS-MELLADO, M. M.

rendimentos e as propriedades do hidrocoloide extraído. Capitani et al. (2015) caracterizaram as propriedades reológicas das dispersões aquosas de mucilagem de chia por dois métodos diferentes (imersão e secagem por congelamento e imersão, filtração, concentração e secagem por congelamento), verificando que a concentração de mucilagem de chia foi a variável que teve efeito significativo sobre o índice de consistência, e a presença de sacarose foi a variável com efeito significativo sobre as características reológicas. Além disso, verificou um aumento nas propriedades reológicas quando houve um aumento das variáveis correspondentes (concentração da mucilagem e presença de sacarose). Muñoz et al. (2012b) verificaram que durante a extração da mucilagem de chia a temperatura e a relação semente-água tiveram um efeito significativo sobre o rendimento. A hidratação da mucilagem extraída foi significativamente aumentada em valores de pH elevado, e a concentração mais elevada em menores teores de sal, sendo máxima quando a temperatura atingiu valores próximos a $80^{\circ} \mathrm{C}$.

\section{Legislação}

A chia já é cultivada comercialmente na Austrália, Bolívia, Colômbia, Guatemala, México, Peru e Argentina, nas províncias de Salta, Jujuy, Tucumán e Catamarca (AYERZA e COATES, 2005; JAMBOONSRI et al., 2012). No Brasil, a chia vem sendo produzida com 3 a 4 meses de cultivo, nos estados de Rio Grande do Sul e São Paulo e segundo o Guia para Comprovação da Segurança de Alimentos e Ingredientes (BRASIL, 2013), a semente de chia é classificada como produtos sem histórico de uso coberto por regulamentos técnicos específicos contidos na petição de avaliação de novos alimentos ou novos ingredientes. Na Argentina, há legislação segundo o Código Alimentario Argentino (2009), art. 1407, que regulamenta a granulometria para farinha de chia $(0,5-1$ $\mathrm{mm})$, bem como os teores máximos de umidade (5\%), lipídios (7\%), fibra total (52\%) e cinzas (6\%), e mínimo de proteína (29\%) da farinha de chia desengordurada. Além disso, há na legislação argentina critérios microbiológicos como apresentado na Tabela 3.

Tabela 3. Critérios microbiológicos segundo o Código Alimentario Argentino (2009).

\begin{tabular}{ll} 
Coliformes totais, máx. & 100 UFC.g ${ }^{-1}$ \\
Coliformes fecais (E. coli) & Ausência em $1 \mathrm{~g}$ \\
Salmonella sp. & Ausência em $25 \mathrm{~g}$ \\
Clostridium sp. (Sulfito redutores) & Ausência em $1 \mathrm{~g}$ \\
$\begin{array}{l}\text { Staphylococcus sp. } \\
\text { Contagem total de fungos e } \\
\text { leveduras, máx. }\end{array}$ & Ausência em $1 \mathrm{~g}$ \\
Aflatoxinas máx. & $100 \mathrm{UFC} \cdot \mathrm{g}^{-1}$ \\
\hline
\end{tabular}

Apesar de todos os benefícios dos compostos presentes na semente de chia demonstrados pela literatura internacional, até 2013 a chia não era reconhecida como um alimento seguro para comercialização pela legislação brasileira, desde que não fosse apresentada em forma farmacêutica. Entretanto, ainda falta muito para a legislação brasileira chegar ao patamar de critérios de qualidade e microbiológicos para a produção e utilização da chia em alimentos comparado à legislação argentina.

\section{Produtos desenvolvidos com adição de chia}

O interesse em estudar a chia como possível aditivo para alimentos surgiu devido ao seu alto teor de antioxidantes, proteínas, fibras e também pelo seu aporte de PUFA, que são benéficos para a saúde. Justo et al. (2007) desenvolveram pão integral adicionado de soja (10\%), chia (5\%), linhaça (5\%) e ácido fólico com a finalidade de obter produtos de maior valor nutritivo e melhores características funcionais. Os pães produzidos com soja adicionados de chia e linhaça tiveram grande aceitação dos consumidores revelada pela avaliação sensorial. Além disso, contiveram maiores teores de proteína (25\%-30\%) em comparação com pães comerciais (21\%). Em particular, os pães adicionados de chia foram ricos em fibra dietética (4\%-5\%) e os resultados sugeriram que os pães apresentaram reduções na captação de glicose no trato digestivo. Outra característica, potencialmente benéfica de saúde, foi o alto conteúdo de PUFA, ômega-9 (em torno de 3\%), ômega-6 (em torno de 3\%), ômega-3 (3\%-4,5\%) e alto conteúdo de cálcio (297 mg.100 g g $^{-1}$-318 mg.100 g g presente nos pães desenvolvidos.

Borneo et al. (2010) avaliaram como a substituição de ovos ou óleo, em uma formulação de bolo, por gel de chia (25\%,50\% e 75\%) afetaria o conteúdo nutricional, as propriedades funcionais básicas e as características sensoriais do produto, em comparação com o controle de óleo e ovo, e observaram que a substituição de ovos ou óleo na formulação de bolo por gel de chia até um nível de $25 \%$ manteve as características funcionais e sensoriais do produto. Puig e Haros (2011) desenvolveram um novo produto de panificação mediante substituição de farinha de trigo por $5 \%$ de sementes de chia e $5 \%$ de farinha integral de chia e concluíram que as sementes de chia ou sua farinha podem ser utilizadas como ingrediente na elaboração de produtos panificados para incrementar o valor nutricional e a qualidade do produto, sendo que o pão adicionado de semente de chia foi o mais aceito pelos consumidores em comparação ao pão adicionado de farinha de chia.

Utpott (2012) desenvolveu maionese adicionada de mucilagem de chia, combinada ou não com outros aditivos emulsificantes, com reduzido teor de óleo e gema de 
COELHO, M. S. e SALAS-MELLADO, M. M.

ovo, e manteve as características funcionais do produto, melhorando seus aspectos sensoriais e tecnológicos. Rendon-Villalobos et al. (2012) desenvolveram tortilhas de milho com adição de 5\%, 10\%, 15\% e 20\% de farinha de chia e todas as formulações apresentaram maiores teores de fibras, proteínas e lipídios que as tortilhas de milho, sendo mais significativa com 15\% e 20\% de substituição. Tombini (2013) desenvolveu uma barra de cereal adicionada de semente de chia que apresentou propriedades físico-químicas e microbiológicas adequadas, com elevado teor de fibra (10,3\%). A aceitabilidade sensorial (84\%) e a intenção de compra (96\%) tiveram resultados satisfatórios.

O grande crescimento do mercado de ácidos graxos essenciais está relacionado com o aumento do consumo de suplementos dietéticos que contenham esses compostos (WARD e SINGH, 2005). Portanto, a incorporação na dieta, de sementes, tais como a chia, que contêm elevado conteúdo desses ácidos graxos, é particularmente desejável. No entanto, um grande desafio para o desenvolvimento de produtos alimentares enriquecidos é apresentado pelos vários critérios de aceitação: o frescor do produto, as características sensoriais, a aparência, as condições de armazenamento, a facilidade de preparação e de normas de segurança, que devem ser alcançadas (DRUSCH e MANNINO, 2009), e os benefícios nutricionais. Pizarro et al. (2013) demonstraram que a incorporação de farinha de chia e reduzido teor de gordura vegetal hidrogenada resultou em um bolo com maior valor nutricional, principalmente nos teores de ácido graxo ômega-3 e a relação ômega-6/ ômega-3. Além disso, foi possível incorporar farinha de chia nas formulações de bolo e obter um produto com boas características tecnológicas (com pequenas variações na firmeza e volume específico) e sensoriais (com escores entre 6, gostei ligeiramente, e 8, gostei muito). Em relação à intenção de compra, esta foi positiva, atingindo $60 \%$ dos julgadores que possivelmente, ou certamente, comprariam o bolo. A presença de gordura vegetal hidrogenada ajuda a minimizar os efeitos adversos da farinha de chia sobre o volume específico e firmeza dos bolos. Os melhores resultados tecnológicos foram obtidos para bolos produzidos com até $15 \mathrm{~g}$ de farinha de chia. $100 \mathrm{~g}^{-1}$ mistura de farinha e de 16 a $20 \mathrm{~g}$ de gordura vegetal hidrogenada. $100 \mathrm{~g}^{-1}$ de mistura de farinha.

Spada et al. (2014) demonstraram que a substituição da carragena, agente espessante comumente utilizado em sobremesas à base de soja, pela mucilagem de chia não proporcionou grandes modificações nas características, tais como $\mathrm{pH}$, grau Brix, coordenada cromática $a^{*}$ e nos atributos sensoriais cor rosa, sabor de goiaba, sabor de soja e cremosidade. A referida substituição teve efeito significativo somente sobre o comportamento reológico do produto, tornando-o menos viscoso, porém também menos pseudoplástico, ou seja, está menos sujeito a mudanças na sua viscosidade durante sua produção.

\section{Conclusão}

É comprovado que a chia (Salvia hispanica L.) é uma boa fonte de gordura poli-insaturada, de ômega-3 e de ômega-6, assim como de fibras e proteínas, e apresenta altos teores de compostos fenólicos com atividade antioxidante. Porém, a utilização dos componentes da chia deve ser mais explorada para utilização em alimentos, tais como:

- Extração de compostos fenólicos de chia e possível aplicação para a redução do escurecimento enzimático, por exemplo, em frutas, quantificando estes compostos após a hidrólise;

- A obtenção de diferentes tamanhos de peptídeos biologicamente ativos que apresentem diferentes propriedades físico-químicas e atividades biológicas, perante processos de hidrólise, para melhorar as propriedades de saudabilidade dos alimentos;

- Maiores estudos sobre os parâmetros para a extração da mucilagem de chia e para a utilização de fibras solúveis como substitutos de emulsificantes nas indústrias de alimentos.

\section{Referências}

ADAMS, R. G.; EVANS, A. J.; OAKENFULL, D. G.; SIDHU, G. S. Fruit Processing Wastes as Dietary Fibre Supplements. Proceedings of the Nutrition Society of Australia, Newcaslte, v. 11, p. 115,1986

AMERICAN HEART ASSOCIATION - AHA. International Cardiovascular Disease Statistics. Dallas: American Heart Association, 2004. 14 p. Disponível em: <http:// www.bellevuecollege.edu/artshum/materials/inter/Spring04/ SizeMatters/internatCardioDisSTATsp04.pdf>.

AYERZA, R.; COATES, W. Chia Seeds: New Source of Omega-3 Fatty Acids, Natural Antioxidants, and Dietetic Fiber. Tucson: Southwest Center for Natural Products Research \& Commercialization, Office of Arid Lands Studies, 2001. 3 p. PMid:11337710

AYERZA, R.; COATES, W. Chia: Rediscovering a Forgotten Crop of the Aztecs. Tucson: The University of Arizona Press, 2005. $215 p$.

AYERZA, R.; COATES, W. Composition of chia (Salvia hispanica) grown in six tropical and subtropical ecosystems of South America. Tropical Science, Germantown, v. 44, n. 3, p. 131-135, 2004. 
Composição química, propriedades funcionais e aplicações tecnológicas da semente de chia (Salvia hispanica L) em alimentos

COELHO, M. S. e SALAS-MELLADO, M. M.

AYERZA, R.; COATES, W.; LAURIA, M. Chia Seed (Salvia hispanica L) as an Omega-3 Fatty Acid Source for Broilers: Influence on Fatty Acid Composition, Cholesterol and Fat Content of White and Dark Meats, Growth Performance, and Sensory Characteristics. Poultry Science, Oxford, v. 81, n. 6, p. 826-837, 2002. http://dx.doi.org/10.1093/ps/81.6.826.

BARROS, L.; CRUZ, T.; BAPTISTA, P.; ESTEVINHO, L. M.; FERREIRA, I. C. F. R. Wild and Commercial Mushrooms as Souce of Nutrients and Nutraceuticals. Food and Chemical Toxicology, Oxford, v. 46, n. 8, p. 2742-2747, 2008. PMid:18538460. http:// dx.doi.org/10.1016/j.fct.2008.04.030.

BORNEO, R.; AGUIRRE, A.; LEÓN, A. E. Chia (Salvia hispanica L) Gel Can be Used as Egg or Oil Replacer in Cake Formulations. Journal of the American Dietetic Association, Chicago, v. 110, n. 6, p. 946-949, 2010. PMid:20497788. http://dx.doi. org/10.1016/j.jada.2010.03.011.

BRASIL. Ministério da Saúde. Agência Nacional de Vigilância Sanitária. Guia para Comprovação da Segurança de Alimentos e Ingredientes. Brasília: ANVISA, 2013. 41 p.

BUSHWAY, A. A.; BELYEA, P. R.; BUSHWAY, R. J. Chia Seed as a Source of Oil, Polysaccharide, and Protein. Journal of Food Science, Chicago, v. 46, n. 5, p. 1349-1350, 1981. http://dx.doi. org/10.1111/j.1365-2621.1981.tb04171.x

CAHILL, J. P. Ethnobotany of Chia, Salvia hispanica L. (Lamiaceae). Economic Botany, New York, v. 57, n. 4, p. 604-618, 2003. http://dx.doi.org/10.1663/0013-0001(2003)057[0604:EOCSHL ]2.0.CO;2.

CAPITANI, M. I.; CORZO-RIOS, L. J.; CHEL-GUERRERO, L. A.; BETANCUR-ANCONA, D. A.; NOLASCO, S. M.; TOMÁS, M. C. Rheological Properties of Aqueous Dispersions of Chia (Salvia hispanica L.) mucilage. Journal of Food Engineering, London, v. 149, p. 70-77, 2015. http://dx.doi.org/10.1016/j. jfoodeng.2014.09.043.

CAPITANI, M. I.; SPOTORNO, V.; NOLASCO, S. M.; TOMÁS, M. C. Physicochemical and Functional Characterization of By-products from Chia (Salvia hispanica L.) Seeds of Argentina. LWT - Food Science and Technology, Oxford, v. 45, n. 1, p. 94-102, 2012. CASTRO-MARTINEZ, R.; PRATT, D. E.; MILLER, E. E. Natural Antioxidants of Chia Seeds. In: WORLD CONFERENCE ON EMERGING TECHNOLOGIES IN THE FATS AND OILS INDUSTRY, 1986, Riverside. Proceedings... Illinois, USA: American Oil Chemists' Society, Champaign, 1986. p. 392-396.

CHICCO, A. G.; D'AlessANDRO, M. E.; HEIN, G. J.; OLIVA, M. E.; LOMBARDO, Y. B. Dietary Chia Seed (Salvia hispanica L.) Rich in a-linolenic acid improves adiposity and normalises hypertriacylglycerolaemia and Insulin Resistance in Dyslipaemic Rats. British Journal of Nutrition, London, v. 101, n. 1, p. 41-50, 2009. PMid:18492301. http://dx.doi.org/10.1017/ S000711450899053X
COATES, W.; AYERZA, R. Production Potential of Chia in Northwestern Argentina. Indutrial Crops and Products, V. 5, n. 3, p. 229-233, 1996. http://dx.doi.org/10.1016/09266690(96)89454-4

CÓDIGO ALIMENTARIO ARGENTINO. Harinas, Concentrados, Aislados y Derivados Proteínicos. 2009. 4 p. (Artículo 1407 bis - (Resolución Conjunta SPRel N 86/2009 y SAGPyA Nº 711/2009)). Disponível em: <http://www.anmat.gov.ar/alimentos/ codigoa/Capitulo_XIX.pdf> Acesso em: 25 mar. 2014.

COELHO, M. S.; SALAS-MELLADO, M. M. Chemical Characterization of Chia (Salvia hispanica L.) for Use in Food Products. Journal of Food and Nutrition Research, v. 2, n. 5 , p. 263-269, 2014. http://dx.doi.org/10.12691/jfnr-2-5-9

COELHO, M. S.; SALAS-MELLADO, M. M. Effects of Substituting Chia (Salvia hispanica L.) Flour or Seeds for Wheat Flour on the Quality of the Bread. LWT - Food Science and Technology, Oxford, v. 60, n. 2, 2015. Part 1. http://dx.doi.org/10.1016/j. Iwt.2014.10.033

CRAIG, R. Application for Approval of Whole Chia (Salvia hispanica L.) Seed and Ground Whole Seed as Novel Food Ingredient. Northern Ireland: Mr D Armstrong, 2004. 29 p. Disponível em: <http://acnfp.food.gov.uk/sites/default/files/mnt/ drupal_data/sources/files/multimedia/pdfs/chiaapplication.pdf>.

CUNDIFF, D. K.; LANOU, A. J.; NIGG, C. R. Relation of Omega-3 Fatty Acid Intake to Other Dietary Factors Knows to Reduce Coronary Heart Disease Risk. American Journal of Cardiology, New York, v. 99, n. 9, p. 1230-1233, 2007. PMid:17478148. http:// dx.doi.org/10.1016/j.amjcard.2006.12.032.

DE LOGERIL, M.; SALEN, P. Mediterranean Diet and -3 Fatty Acids in the Prevention and Treatment of Cardiovascular Disease. Journal of Cardiovascular Medicine, New York, v. 8, p. 38-41, 2007. Suplemento 1.

DECKER, E. A. Phenolics: Prooxidants or Antioxidants? Nutritional Reviews, v. 55, n. 1, p. 396-398, 1997. PMid:9420450.

DORMAN, H. J. D.; KOSAR, M.; KAHLOS, K.; HOLM, Y.; HILTUNEN, R. Antioxidant Properties and Composition of Aqueous Extracts from Mentha Species, Hybrids, Varieties, and Cultivars. Journal of Agricultural and Food Chemistry, Washington, v. 51, n. 16, p. 4563-4569, 2003. PMid:14705878. http://dx.doi.org/10.1021/jf034108k.

DRUSCH, S.; MANNINO, S. Patent-based Review on Industrial Approaches for the Microencapsulation of Oils Rich in Polyunsaturated Fatty Acids. Trends in Food Science and Technology, Cambridge, v. 20, n. 6-7, p. 237-244, 2009. http:// dx.doi.org/10.1016/j.tifs.2009.03.007.

DUNN, J. The Chia Company Seeks Entry Into European Market. Australian Food News, 2010. Disponível em: <http:// www.ausfoodnews.com.au/2010/02/08/the-chia-companyseeks-entry-into-european-market.html>. Acesso em: 15 jul. 2012. 
Composição química, propriedades funcionais e aplicações tecnológicas da semente de chia (Salvia hispanica L) em alimentos

COELHO, M. S. e SALAS-MELLADO, M. M.

GÔMES, J. A. H.; COLÍN, S. M. Caracterización Morfológica de Chia (Salvia hispanica L). Revista Fitotecnia Mexicana, Mexico, v. 31, n. 2, p. 105-113, 2008.

GRIGELMO-MIGUEL, N.; MARTíN-BELLOSO, O. Characterization of Dietary Fiber from Orange Juice Extraction. Food Research International, Essex, v. 31, n. 5, p. 355-361, 1998. http://dx. doi. org/10.1016/S0963-9969(98)00087-8.

HU, F. B. Dietary Patterns Analysis: A New Direction in Nutritional Epidemiology. Current Opinion Lipidology, London, v. 13, n. 1, p. 3-9, 2002. http://dx.doi.org/10.1097/00041433-20020200000002.

IXTAINA, V. Y.; MARTÍNEZ, M. L.; SPOTORNO, V.; MATEO, C. M.; MAESTRI, D. M.; DIEHL, B. W. K. Characterization of Chia Seed Oils Obtained by Pressing and Solvent Extraction. Journal of Food Composition Analysis, San Diego, v. 24, n. 2, p. 166-174, 2011. http://dx.doi.org/10.1016/j.jfca.2010.08.006.

IXTAINA, V. Y.; NOLASCO, S. M.; TOMÁS, M. C. Physical Properties of Chia (Salvia hispanica L.) Seeds. Industrial Crops and Products, v. 28, n. 3, p. 286-293, 2008. http://dx.doi. org/10.1016/j.indcrop.2008.03.009.

IXTAINA, V. Y.; VEGA, A.; NOLASCO, S. M.; TOMÁS, M. C.; GIMENO, M.; BÁRZANA, E.; TECANTE, A. Supercritical Carbon Dioxide Extraction of Oil from Mexican Chia Seed (Salvia hispanica L.); Characterization and Process Optimization. Journal of Supercritical Fluids, v. 55, n. 1, p. 192-199, 2010. http://dx.doi.org/10.1016/j.supflu.2010.06.003.

JAMBOONSRI, W.; PHILLIPS, T. D.; GENEVE, R. L.; CAHILL, J. $P$. Extending the Range of an Ancient Crop, Salvia hispanica L. - A New $\omega-3$ Source. Genetic Resources Crop Evolution, Dordrecht, v. 59, n. 2, p. 171-178, 2012. http://dx.doi. org/10.1007/s10722-011-9673-x

JIN, F.; NIEMAN, D.C.; SHA, W.; XIE, G.; QIU, Y.; JIA, W. Suplementation of Milled Chia Seeds Increases Plasma ALA and EPA in Postmenopausal Women. Plasts Food for Human Nutrition, Kannapolis, v. 67, n. 2, p. 105-110, 2012.

JUSTO, M. B.; ALFARO, A. D. C.; AGUILAR, E. C.; WROBEL, K.; WROBEL, K.; GUZMÁN, G. A.; SIERRA, Z. G.; ZANELLA, V. M. Desarrollo de Pan Integral con Soya, Chía, Linaza y Ácido Fólico como Alimento Funcional para la Mujer. Archivos Latinoamericanos de Nutricion, Caracas, v. 57, n. 1, p. 78-84, 2007.

KIM, K. H.; TSAO, R.; YANG, R.; CUI, S. W. Phenolic Acid Profiles and Antioxidant Activities of Wheat Bran Extracts and the Effect of Hydrolysis Conditions. Food Chemistry, Barking, v. 95, n. 3 , p. $466-473,2006$

KITZBERGER, C. S. G. Obtenção de extrato de cogumelo Shiitake (Lentinula edodes) com CO2 a alta pressão. 2005. 128 f. Dissertação (Mestrado em Engenharia de Alimentos)Centro Tecnológico, Universidade Federal de Santa Catarina, Florianópolis, 2005.
LIN, K. Y.; DANIEL, J. R.; WHISTLER, R. L. Struture of Chia Seed Polysaccharide Exudates. Carbohydrate Polymers, Amsterdam, v. 23, n. 1, p. 13-18, 1994. http://dx.doi.org/10.1016/01448617(94)90085-X

MARIN, F. M.; ACEVEDO, M. J.; TAMEZ, R. M.; NEVERO, M. J.; GARAY, A. L. Method for Obtaining Mucilage from Salvia hispanica L. ES n. WO/2008/0044908, 12 out. 2007, 17 abr. 2008.

MENDONÇA, S. N. T. G. Nutrição. Curitiba: Livro Técnico, 2010. p. 84-96.

MORAES, F. P.; COLLA, L. M. Functional Foods and Nutraceuticals: Definition, Legislation and Health Benefits. Brazilian Journal of Pharmaceutical Sciences, São Paulo, v. 3, n. 2, p. 99-112, 2006.

MUÑOZ, L. A.; AGUILERA, J. M.; RODRIGUEZ-TURIENZO, L.; COBOS, A.; DIAZ, O. Characterization and Microstructure of Films Made from Mucilage of Salvia hispanica and Whey Protein Concentrate. Journal of Food Engineering, London, v. 111, n. 3, p. 511-518, 2012a. http://dx.doi.org/10.1016/j. jfoodeng.2012.02.031.

MUÑOZ, L. A.; COBOS, A.; DIAZ, O. AGUILERA, J. M. Chia Seeds: Microstructure, Mucilage Extraction and Hydration. Journal of Food Engineering. London, v. 108, n. 1, p. 216-224, 2012b.

NACZK, M.; SHAHIDI, F. Extraction and Analysis of Phenolics in Food. Journal of Chromatography A, New York, v. 1054, n. 1-2, p. 95-111, 2004.

OLIVOS-LUGO, B. L.; VALDIVIA-LÓPEZ, M. Á.; TECANTE, A. Thermal and Physicochemical Properties and Nutritional Value of the Protein Fraction of Mexican Chia Seed (Salvia hispanica L.). Food Science and Technology International, Oxford, v. 16, n. 1, p. 89-96, 2010. PMid:21339125. http://dx.doi. org/10.1177/1082013209353087

PAREDES-LÓPEZ, O.; ORDORICA-FALOMIR, C.; GUEVARALARA, F.; COVARRUBIAS, M. M. Las Proteínas Vegetales: Presente y Futuro de la Alimentación. In: PERSPECTIVA de la Biotecnología en Mexico. Quintero, Mexico: Fundación Javier Barrios Sierra, 1985. p. 331-350.

PEIRETTI, P. G.; GAI, F. Fatty Acid and Nutritive Quality of Chia (Salvia hispanica L.) Seeds and Plant During Growth. Animal Feed Science and Technology, Amsterdam, v. 148, n. 2-4, p. 267-275, 2009. http://dx.doi.org/10.1016/j. anifeedsci.2008.04.006.

PIZARRO, P. L.; ALMEIDA, E. L.; SAMMÁN, N. C.; CHANG, Y. K. Evaluation of Whole Chia (Salvia hispanica L.) Flour and Hydrogenated Vegetable Fat in Pound Cake. Food Science and Technology, Oxford, v. 54, n. 1, p. 73-79, 2013.

PRAKASH, A.; RIGELHOF, F.; MILLER, E. Antioxidant Activity. Minneapolis: Medallion Labs. 4 p. Disponível em: <http://www. medlabs.com/downloads/antiox_acti_.pdf>. Acesso em: 14 jan. 2014. 
Composição química, propriedades funcionais e aplicações tecnológicas da semente de chia (Salvia hispanica L) em alimentos

COELHO, M. S. e SALAS-MELLADO, M. M.

PUIG, E. I.; HAROS, M. La Chia en Europa: El Nuevo Ingrediente en Productos de Panadería. Alimentaria, Lugo, v. 420, p. 73-77, 2011.

RENDON-VILLALOBOS, R.; ORTIZ-SANCHEZ, A.; SOLORZAFERIA, J.; TRUJILLO-HERNANDEZ, C. A. Formulation, Physicochemical, Nutritional and Sensorial Evaluation of Corn Tortillas Supplemented with Chía Seed (Salvia hispanica L.). Czech Journal of Food Science, Czech Republic, v. 30, n. 2, p. 118-125, 2012

REYES-CAUDILLO, E.; TECANTE, A.; VALDIVIA-LÓPEZ, M. A. Dietary Fibre Content and Antioxidant Activity of Phenolic Compounds Present in Mexican Chia (Salvia hispanica L.) Seeds. Food Chemistry, Barking, v. 107, n. 2, p. 656-663, 2008. RISPAIL, N., MORRIS, P.; WEBB, K. Phenolic Compounds: Extraction and Analysis. In: MÁRQUEZ, A. (Ed.). Lotus Japonicus Handbook. Berlin: Springer, 2005. p. 349-354. http:// dx.doi.org/10.1007/1-4020-3735-X_34.

RUPFLIN, D. I. A. Caracterización de la Semilla Del Chan (Salvia hispanica L.) y Diseño de um Producto Funcional que la Contiene como Ingrediente. Revista $\mathbf{2 3}$ de la Universidad del Valle de Guatemala, Guatemala, p. 43-49, 2011.

SAHAGUN, B. Historia General de Las Cosas de Nueva España. México: Editorial Porrua, 1989. PMid:2757116 PMCid:PMC1879935.

SANDOVAL-OLIVEROS, M. R.; PAREDES-LÓPEZ, O. Isolation and Characterization of Proteins from Chia Seeds (Salvia hispanica L.). Jounal of Agricultural and Food Chemistry, Washington, v. 61, n. 1, p. 193-201, 2013. PMid:23240604. http:// dx.doi.org/10.1021/jf3034978.

SEGURA-CAMPOS, M. R.; SALAZAR-VEGA, I. M.; CHELGUERRERO, L. A.; BETANCUR-ANCONA, D. A. Biological Potential of Chia (Salvia hispanica L.) Protein Hydrolysates and Their Incorporation Into Functional Foods. Food Science and Technology, London, v. 50, n. 2, p. 723-731, 2013.

SEGURA-NIETO, M.; BARBA DE LA ROSA, A. P.; PAREDESLÓPEZ, O. Biochemistry of amaranth protein. In: PAREDES-LÓPEZ, O. (Ed.). Amaranth: Biology, Chemistry and Technology. Boca Raton: CRC Press, 1999. p. 76-95.

SHEWRY, P. R. Cereal Seed Storage Proteins: Structures, Properties and Role in Grain Utilization. Journal of Experimental
Botany, Oxford, v. 53, n. 370, p. 947-958, 2002. http://dx.doi. org/10.1093/jexbot/53.370.947

SIMÕES, C. M. O.; SCHENKEL, E. P.; GOSMANN, G.; MELLO, J. C. P.; MENTZ, L. A.; PETROVICK, P. R. Farmacognosia: Da Planta ao Medicamento. 2. ed. Porto Alegre: UFRGS, 2000. 1104 p. PMCid:PMC2620449.

SPADA, J. C.; DICK, M.; PAGNO, C. H.; Vieira, A. C.; BERNSTEIN; A.; COGHETTO, C.C.; MARCZAK; L. D. F.; TESSARO; I. C.; CARDOZO; N. S. M.; FLÔRES, S. H. Physical, Chemical and Sensory Characterization of Soy-based Desserts Made with Chia Mucilage. Ciência Rural, Santa Maria, v. 44, n. 2, p. 374-379, 2014. http://dx.doi.org/10.1590/S0103-84782014000200029.

TAGA, M. S.; MILLER, E. E.; PRATT, D. E. Chia Seeds as a Source of Natural Lipids Antioxidants. Journal of the American Oil Chemistry Society, Champaign, v. 61, n. 5, p. 928-993, 1984. http://dx.doi.org/10.1007/BF02542169.

TOMBINI, J. Aproveitamento Tecnológico da Semente de Chia (Salvia Hispanica L.) na Formulação de Barra Alimentícia. 2013. 36 f. Monografia (Bacharelado em Química)-Universidade Tecnológica Federal do Paraná, Pato Branco, 2013.

TOSCO, G. Os Benefícios da "Chia" em Humanos e Animais. Atualidades Ornitológicas, n. 119, p. 7, 2004.

UTPOTT, M. Utilização da Mucilagem da Chia (Salvia hispanica L.) na Substituição de Gordura e/ou Gema de Ovo em Maionese. 2012. 50 f. Monografia (Bacharelado em Engenharia de Alimentos)-Universidade Federal do Rio Grande do Sul, Porto Alegre, 2012.

WARD, O. P.; SINGH, A. Omega-3/6 Fatty Acids: Alternative Sources of Production. Process Biochemistry, London, v. 40, p. 3627-3652, 2005. http://dx.doi.org/10.1016/j. procbio.2005.02.020

WEBER, C. W.; GENTRY, H. S.; KOHLHEPP, E. A.; MCCROHAN, P. R. The Nutricional and Chemical Evaluation of Chia Seeds. Ecology of Food and Nutrition, v. 26, p. 119-125, 1991. http:// dx.doi.org/10.1080/03670244.1991.9991195.

ZAMBOM, M. A.; SANTOS, G. T.; MODESTO, E. C. Importância das Gorduras Poli-insaturadas da Saúde Humana. Revista Sociedade Brasileira de Zootecnia, Viçosa, v. 547, p. 553-557, 2004. 